Revistade
Economild
Contemporâned

\title{
RESENHA BIBLIOGRÁFICA: ECONOMIA INSTITUCIONAL: FUNDAMENTOS TEÓRICOS E HISTÓRICOS, DE ALEXANDRE OTTONI TEATINI SALLES, HUÁSCAR FIALHO PESSALI E RAMÓN GARCIA FERNÁNDEZ (SÃO PAULO: EDITORA UNESP, 2017)
}

\begin{abstract}
Carolina Miranda Cavalcante ${ }^{a}$

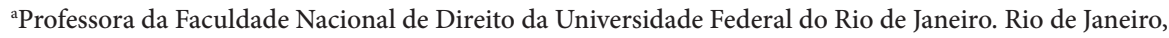
RJ, Brasil. ORCID: https://orcid.org/0000-0001-8843-891X.

Recebido em 13 fevereiro 2020

Aceito em 02 julho 2020

RESUMO: Resenha bibliográfica do livro Economia Institucional: fundamentos teóricos e históricos, da autoria de Alexandre Ottoni Teatini Salles, Huáscar Fialho Pessali e Ramón Garcia Fernández, publicado pela Editora UNESP, de São Paulo, em 2017.
\end{abstract}

PALAVRAS-CHAVE: Thorstein Veblen; institucionalismo americano; pensamento institucionalista contemporâneo.

CLASSIFICAÇÃO JEL: B15, B25, B52. 


\section{BOOK REVIEW: ECONOMIA INSTITUCIONAL: FUNDAMENTOS TEÓRICOS E HISTÓRICOS, BY ALEXANDRE OTTONI TEATINI SALLES, HUÁSCAR FIALHO PESSALI, AND RAMÓN GARCIA FERNÁNDEZ (SÃO PAULO: EDITORA UNESP, 2017)}

ABSTRACT: Book review of the title Economia Institucional: fundamentos teóricos e históricos, by Alexandre Ottoni Teatini Salles, Huáscar Fialho Pessali, and Ramón Garcia Fernández, published by Editora UNESP, São Paulo, Brazil, 2017.

KEYWORDS: Thorstein Veblen; American institucionalism; contemporary institutionalist thought. 
O livro compila, em quatro partes, artigos que discutem temáticas concernentes à velha economia institucional, ou institucionalismo original, como preferem os organizadores do livro. Nesse conjunto de 12 artigos, autores fundadores do institucionalismo original e autores institucionalistas contemporâneos, apresentam as bases dessa escola de pensamento inaugurada pela obra de Thorstein Veblen, bem como algumas questões relativas à precisão conceitual e à demarcação do campo de estudos institucionalista. Essa coletânea de artigos tem o mérito de traduzir artigos importantes para o português, preenchendo uma enorme lacuna no campo de estudos institucionalista brasileiro, além de trazer artigos inéditos de institucionalistas brasileiros contemporâneos.

O livro é prefaciado por Geoffrey Hodgson, um dos maiores divulgadores do pensamento institucionalista nas ciências sociais. Hodgson assinala a proeminência do institucionalismo original, liderado por Thorstein Veblen, John Commons e Wesley Mitchell, na academia norte-americana no início do século XX. O autor discute ainda a cisão no pensamento institucionalista com a emergência de uma vertente novo institucionalista no pós-Segunda Guerra, liderada por Ronald Coase, Oliver Williamson, Elinor Ostrom e Douglass North - todos os quatro agraciados com o Nobel de Economia. Embora o novo institucionalismo tenha se tornado uma espécie de mainstream da economia institucional, autores como John Kenneth Galbraith e Gunnar Myrdal teriam dado continuidade à proposta original do pensamento institucionalista. Para além de uma abordagem institucionalista no campo da economia, Hodgson aponta ainda para ramificações dessa abordagem em outras disciplinas do pensamento social, como o emergente campo do institucionalismo jurídico, que teve suas primeiras ideias elaboradas por Commons.

Alexandre Salles, Huáscar Pessali e Ramón Fernández, organizadores desta coletânea de artigos, deixam clara sua proposta de trazer ao público acadêmico obras fundamentais para o estudo do institucionalismo original. Uma das contribuições do livro é justamente a oferta de artigos seminais e contemporâneos sobre economia institucional em língua portuguesa, algo tão escasso. Contudo, o mérito do livro não se circunscreve à tradução de artigos, posto que sugere uma agenda de pesquisa institucionalista. Apesar de abarcar um conjunto amplo de autores, bem como um espectro temporal que segue do final do século XIX ao primeiro quarto do século XXI, o livro possui um fio condutor claro que leva o leitor desde o debate concernente ao conceito de instituição, passando pelo intrincado problema da dupla determinação entre ação humana e instituições, até o caráter interdisciplinar do institucionalismo original. Esses são temas presentes em diversos dos 12 artigos que compõem o livro.

Em artigo originalmente publicado em 1919, traduzido na presente coletânea como "A abordagem institucional para a teoria econômica", Walton Hamilton sugere 
pela primeira vez o termo "economia institucional" como uma denominação para as teorias que autores como Veblen e Mitchell vinham elaborando. Na ocasião da publicação desse artigo de Hamilton, o que se considerava uma abordagem institucionalista se restringia, naturalmente, apenas ao que hoje classificamos como institucionalismo original, uma vez que o novo institucionalismo não havia entrado em cena. Nesse sentido, uma classificação para as ideias que Veblen desenvolvia desde o final do século XIX só apareceu duas décadas depois. Em 1898, Veblen publicaria o artigo que é considerado a obra inaugural do institucionalismo original e que abre a coletânea de artigos deste livro: “Por que a economia não é uma ciência evolucionária?". Nele, Veblen tece críticas à modalidade de construção teórica da teoria econômica de sua época, que não se constituía em ciência evolucionária por ser taxonômica, animista e hedonista. Importante notar que as críticas de Veblen permanecem atuais, podendo ser direcionadas a uma modalidade de construção teórica formalística própria da teoria neoclássica contemporânea.

O terceiro artigo, que encerra a parte I - Origem e Fundamentos do Institucionalismo -, é um clássico trabalho de Commons, publicado originalmente em 1931, intitulado "Economia institucional". Nesse artigo, Commons menciona a dificuldade em definir instituição, que ora parece significar o conjunto de regras às quais os indivíduos se submetem, ora parece remeter ao próprio comportamento desses indivíduos. Essa dificuldade permanece até hoje no campo de estudos institucionalistas, remetendo a uma questão recorrente e mais ampla do pensamento social - a relação entre ação humana e estruturas sociais. Commons sugere ainda uma ideia fundamental para os estudos no campo do institucionalismo jurídico, a saber, a ideia de transação enquanto relação jurídica, relacionada à propriedade, que precederia a troca mercantil, uma relação econômica. Nessa primeira parte, na qual são apresentados autores seminais do institucionalismo original, o leitor pode sentir falta do trabalho de Wesley Mitchell, autor fundamental não apenas para o institucionalismo, mas para a própria história das contas nacionais e, consequentemente, da macroeconomia.

A parte II - O Conceito de Instituições na Literatura Contemporânea - reúne três artigos que debatem explicitamente o conceito de instituição. Artigo de Walter Neale originalmente publicado em 1987, "Instituições" busca definir não apenas o termo “instituição", mas o próprio campo institucionalista. O autor se embrenha em debates espinhosos envolvendo o conceito de regras e cultura, debates esses que seriam retomados mais tarde por Hodgson, por exemplo, no artigo publicado em 2006, vertido para o português nessa coletânea sob o título “O que são instituições?”. Nesse artigo, Hodgson busca esclarecer conceitos como o de regras, normas e organizações, no sentido de construir uma definição mais clara de instituição. Além de contribuir substancialmente para esse debate, o artigo de Hodgson traz ao final uma interessante 
troca de correspondências do autor com Douglass North. O terceiro artigo da parte II, "O conceito de instituições e algumas tipologias", de autoria de David Dequech, retoma as questões conceituais indicadas por Neale e Hodgson, chamando atenção para uma dimensão cognitiva das instituições.

A parte III - Teoria, História e Método do Institucionalismo - traz artigos que discutem a relevância do institucionalismo original, o confrontando com a teoria neoclássica e o novo institucionalismo. $\mathrm{O}$ artigo "O início do institucionalismo", de Anne Mayhew, discute as influências teóricas na obra de Veblen e Commons, desmistificando algumas leituras simplistas acerca de uma suposta filiação dos autores à escola histórica alemã e ao marxismo. A autora aponta ainda o contexto histórico da emergência do institucionalismo norte-americano como importante para entender as proximidades e os distanciamentos teóricos de autores como Veblen e Commons ao pensamento que emanava da Europa, dos clássicos ingleses até o historicismo alemão, passando pela proposta radical do marxismo. O artigo de Karl William Kapp, "A natureza e a relevância da economia institucional”, traça diferenças importantes entre a economia neoclássica e o institucionalismo econômico. $\mathrm{O}$ autor destaca o caráter multidisciplinar da economia institucional, bem como sua atenção à análise empírica e a uma visão mais ampla do econômico enquanto parte do ambiente social e ecológico. $\mathrm{O}$ artigo de Geoffrey Hodgson, "A abordagem da economia institucional”, segue um caminho semelhante ao destacar diferenças entre a nova economia institucional e o que ele denomina como antigo institucionalismo norte-americano. Hodgson discute alguns motivos que teriam levado ao relativo esquecimento das teorias de Veblen, Commons e Mitchell, assinalando que esses autores não apenas anteciparam ideias que seriam desenvolvidas mais tarde por autores como North, Hayek e Simon, mas apontando ainda a atualidade e relevância do institucionalismo antigo para a teoria econômica.

O livro se encerra com a parte IV - Elementos para uma Agenda de Pesquisa -, na qual reconhecidos institucionalistas brasileiros discutem o potencial da teoria institucionalista original nos dias de hoje. O artigo "Uma avaliação da agenda de pesquisa da escola institucionalista original", de Octavio Augusto Camargo da Conceição, dialoga com a tentativa de Hamilton (capítulo 2 desta coletânea) de sugerir uma agenda institucionalista unificada. Conceição destaca o caráter essencialmente evolucionário do pensamento de Veblen, apontando uma aproximação - uma quase fusão - entre a economia institucional e a economia evolucionária. O penúltimo artigo da coletânea, "Para além do consumo conspícuo", de autoria de Alexandre Salles e Rafael Camatta, busca apresentar a relevância e a atualidade do pensamento de Veblen para a construção de uma teoria do consumo institucionalista. Os autores analisam não apenas o conceito de consumo conspícuo, mas também a ideia de consumo de 
bens padronizados. Por fim, o artigo "As competências institucionais de Hercules a partir da aproximação entre Veblen e Penrose”, de autoria de Felipe Almeida e Huáscar Pessali, sugere uma aproximação entre as ideias de Veblen e a concepção de firma de Edith Penrose.

Em seu conjunto, os 12 artigos trazem um debate teórico acerca do conceito de instituição e sua relação com a ação humana, trabalhada no âmbito da ideia de causação cumulativa de Geoffrey Hodgson, discutindo ainda o lugar do institucionalismo original na economia institucional e na ciência econômica. Ao longo dos artigos é possível observar um esforço no sentido da proposição de uma agenda de pesquisa institucionalista unificada. O retorno aos autores institucionalistas seminais estabelece e identifica as raízes da proposta de um institucionalismo contemporâneo não neoclássico. Embora sejam traçadas diferenças importantes em relação à nova economia institucional, são reconhecidos elementos comuns no campoinstitucionalista, como a ideia de modelos mentais, assinalada por Dequech (artigo 6), e de regras como componentes inerentes às instituições, indicada por Hodgson (artigo 5). Contudo, a fonte desse institucionalismo contemporâneo alternativo permanece nos autores seminais do institucionalismo original. Principalmente nos artigos da parte IV do livro, os autores ilustram como um institucionalismo contemporâneo de raiz vebleniana seria capaz de tratar tanto de questões macroeconômicas concernentes ao processo evolucionário quanto de questões microeconômicas relativas à firma e ao consumidor. Nesse sentido, o livro é uma contribuição essencial para o reconhecimento das origens da economia institucional, bem como para a construção de um institucionalismo contemporâneo não neoclássico, ainda que não isolado de um debate com outras vertentes do pensamento institucionalista.

\section{REFERÊNCIAS}

COMMONS, J. R. Institutional economics. American Economic Review, v. 21, n. 4, p. 648-657, 1931.

HAMILTON, W. H. The institutional approach to economic theory. American Economic Review, v. 9, n. 1, p. 309-318, 1919.

HODGSON, G. M. What are institutions? Journal of Economic Issues, v. 40, n. 1, 2006.

KAPP, K. W. The nature and significance of institutional economics. Kyklos, v. 29, p. 209-232, 1976.

MAYHEW, A. The beginnings of institutionalism. Journal of Economic Issues, v. 21, n. 3, p. 971998, 1987.

NEALE, W. Institutions. Journal of Economic Issues, v. 21, n. 3, p. 1177-1205, 1987. 
SALLES, A. O. T.; PESSALI, H. F.; FERNÁNDEZ, R. G. Economia Institucional: fundamentos teóricos e históricos. São Paulo: Editora Unesp, 2017.

VEBLEN, T. B. Why is economics not an evolutionary science? The Quarterly Journal of Economics, v. 12, n.4, p. 373-397, 1898. 